\title{
The relationship of resilience, hardiness, depression and burnout among J apanese psychiatric hospital
} nurses

\author{
Masao Gito ${ }^{1,2}$, Hiroshi I hara' ${ }^{1}$, Hiroyuki Ogata ${ }^{1}$ \\ 1. Department of Psychiatry, Dokkyo Medical University Koshigaya Hospital, Saitama, Japan. 2. Department of Psychiatry, \\ I kezawa Hospital, Saitama, Japan
}

Correspondence: Hiroshi IHARA, MD, PhD. Address: Department of Psychiatry, Dokkyo Medical University Koshigaya Hospital, 2-1-50 Minami-Koshigaya, Koshigaya City, Saitama Prefecture, Japan. Telephone: 81-48-965-1111. Email: cotoncb@dokkyomed.ac.jp.

Received: December 30, 2012

Accepted: February 15, $2013 \quad$ Online Published: April 15, 2013

DOI : 10.5430/jnep.v3n11p12

URL: http://dx.doi.org/10.5430/jnep.v3n11p12

\section{Abstract}

Objectives: Psychological resilience is considered to be the ability of an individual to adjust positively to adversity. This study was conducted to examine the resilience of nurses in psychiatric hospitals in Japan. Two hypotheses tested were: 1) their resilience is negatively correlated to their depression and burnout; 2) their resilience is positively correlated to their hardiness and self-esteem

Method: To identify the magnitude of individuals' resilience, a 32-item 'Resilience Scale for Nurses' (RSN) was administered to 327 nurses employed at three psychiatric hospitals in Japan. For the purpose of evaluating the correlation of resilience with other measures, psychological scales relevant to the RSN were also employed, such as the 'Japanese Self-Esteem Scale', the 'Japanese Hardiness Scale 20', the 'Japanese version of the Beck Depression Inventory', and the 'Japanese version of Burnout Scale'.

Results: A total of 313 nurses responded to the questionnaire (95.7\% response rate). The principal factor method suggested a three-factor solution, consisting of 'Positivity in nursing', 'Interpersonal skills', and 'Adaptability in the workplace'. The levels of Cronbach's alpha for the overall RSN $(.74)$ as well as each of the three factors $(.64 ; .63 ; .61$, respectively) were respectable. Positive correlations of the RSN were found with the Self-Esteem Scale $(.38 ; p<.01)$ and the Hardiness Personality Scale $(.47$ and $.27 ; p<.01)$, and negative correlations of the RSN were found with the Beck Depression Inventory $(-.26 ; p<.01)$ and the Burnout Scale $(-.31,-.27$ and $-.30 ; p<.01)$.

Conclusions: The levels of Cronbach's alpha supported the internal consistency reliability of the RSN. All of the three factors reflected characteristics of resilience as had already been indicated by the previous studies, supporting the construct validity of the RSN. Significant correlations of the RSN with well-established measures of mental health provided evidence for the two hypotheses.

\section{Key words}

Resilience, Nurse, Burnout, Depression, Hardiness 


\section{I ntroduction}

Workplace adversity in health care settings has been discussed widely in the international literature of nursing management during the past few decades. Today nurses are inevitably confronted with a variety of work-related challenges ${ }^{[1,2]}$. These include serious understaffing, shortage of well-experienced nurses, an ageing workforce, a great increase of short-term contracted staff, and interpersonal issues such as bullying, abuse and harassment ${ }^{[3,4]}$.

Above all, nurses working for psychiatric hospitals have another risk of falling in adversity: violence ${ }^{[5]}$. For psychiatric hospitals, nurses are the frontline professional staff. Violence has been an apprehension for staff in psychiatric hospitals ${ }^{[6]}$. For long periods of time when patients may have less control, nurses have been at the greatest risk of violence among hospital staff. The risk of assault on the job negatively influences nurses' intention to stay on remain ${ }^{[7]}$.

These problems have bitterly disappointed and demoralized even the most competent nurses who have noticed their working environment as hostile and unrewarding. It is not surprising that many of them endure emotional burnout, suffer from depression and eventually end up abandoning their profession.

Amongst these aggravating situations there are two types of nurses: those who experience burnout, depression and intention to leave their jobs and those who remain, survive and even thrive. This raises the question of why some nurses are able to cope with workplace adversity and find job satisfaction, but others are not. We suggest that the concept of 'resilience' affords an essential key to an understanding of the survival of nurses.

Personal resilience is considered to be the resource of an individual to positively adjust to adversity ${ }^{[8,9]}$ and move on in a productive way from traumatic or stressful experiences ${ }^{[10,11]}$. Such a resilient resource exerts its strength when facing a stressful psychological whirlwind. Resilience is taken as the opposite of vulnerability in Rutter's ${ }^{[12]}$ proposed model of a continuum ranging between the two poles of vulnerability and resilience.

Although there is a broad consensus on the concept of resilience among these studies, resilience itself has rarely been measured. This is owing mainly to the paucity of a psychometric scale developed for assessing the degree of resilience. The absence of a rating tool has prevented empirical research concerning the relationship between resilience and mental health issues like depression, burnout and self-esteem in nursing. Besides, to our knowledge, nurses working for psychiatric hospitals have rarely been studied concerning their resilience despite putative high-risk characteristics. Moreover, due perhaps to a language barrier, no studies published in journals in the English language have addressed the issue of resilience in hospital settings in Japan.

Taking these concerns into account, this study was conducted to examine the resilience of nurses in psychiatric hospitals in Japan. For this purpose, we administered a Japanese 32-item scale called 'Resilience Scale for Nurses' (RSN) ${ }^{[13,14]}$, whose reliability has already been evaluated psychometrically. Our research questions concerning nurses in psychiatric hospitals were as follows: 1) is their resilience negatively related to their depression and burnout? and is their resilience positively related to their hardiness and self-esteem?

\section{Materials and methods}

\subsection{Subjects}

This study started after receiving approval from the ethics committee of the hospital where the authors were affiliated. Data were obtained at three psychiatric hospitals located in rural areas of Japan. At the time of data collection there were 327 nurses employed at these hospitals. All questionnaires were distributed and returned via the nurse manager of each station. To keep confidentiality and anonymity, the questionnaires were returned in a self-addressed sealed envelopes. A total of 313 nurses responded to the questionnaire (95.7\% response rate). 


\subsection{Methods}

The 'Resilience Scale for Nurses' (RSN) was administered to identify the level of an individual's resilience. The RSN is a 32-item questionnaire written in plain Japanese for assessing the degree of resilience, specifically among nurses. On 429 subjects, reliability was determined by (1) a split-half method where estimated predicted reliability .77 was obtained, and (2) Cronbach's alpha where the overall RSN .84 was estimated ${ }^{[13,14]}$.

\subsection{Measures}

To measure nurses' self-esteem, hardiness, depression and burnout, the following scales were administered: the Japanese Self-Esteem Scale (Japanese translation of the Rosenberg Scale ${ }^{[15,16]}$ ); the Japanese Hardiness Scale $20{ }^{[17]}$; the Japanese version of the Beck Depression Inventory ${ }^{[18]}$ and the Japanese version of the Burnout Scale ${ }^{[19]}$. The Japanese Self-Esteem Scale is a ten item Likert scale that measures a person's overall evaluation of his/her own worth. The Japanese Hardiness Scale 20 is a 20 -item Likert scale developed to investigate a resistance resource against life stress. Beck Depression Inventory is a multiple-choice self-report inventory for measuring the severity of depression. The Burnout Scale is a 22 item Likert Scale to measure the experience of long-term exhaustion and diminished interest. We expected there would be positive correlation between the RSN and the Japanese Self-Esteem Scale and between the RSN and the Hardiness Scale 20 and negative correlation between the RSN and Beck Depression Inventory and between the RSN and the burnout Scale.

By means of a numerical coding system, all data were guarded under strict confidentiality and anonymity. The data were analyzed by SPSS 11.0J for Windows. The factor structure of the RSN was examined using principal factor method. The internal consistency reliability of the RSN was calculated by alpha coefficient. Bivariate relationships were explored by correlational analyses between the RSN and other scales.

\section{Results}

\subsection{Demographic characteristics of nurses and workplace}

There were 253 (80.8\%) nurses and 60 (19.2\%) male nurses. The respondents consisted of $231(73.8 \%)$ married nurses and $82(26.2 \%)$ unmarried nurses. The duration of nursing experience in total was as follows: $6(2 \%)$ under 1 year; $19(6.4 \%) 1$ to 4 years; 46 (15.4\%) 5 to 9 years; 85 (28.4\%) 10 to 19 years; and 143(47.8\%) 20 years and over. The duration of the employment at the hospital where data were taken was as follows: $19(6.3 \%)$ under 1 year; $74(24.6 \%) 1$ to 4 years; 97 (32.2\%) over 5 to 9 years; 54 (17.9\%) 10 to 19 years; and 57(18.9\%) 20 years and over.

\subsection{Factorial structure of the RSN}

The 32-item RSN was analyzed using principal factor method. Considering the transition of eigenvalues $(6.56,2.92,1.66$, $1.62,1.52 \ldots)$ and the interpretability of factor solutions of three-, four- and five-factors, a three-factor solution proved to be more interpretable. Thus, expecting to observe a three-factor structure, principal factor method was applied, followed by Promax rotation. Excluding 14 items with factor loadings of less than 0.5, again, principal factor method was administered, followed by Promax rotation. A three-factor solution proved to be more interpretable. Factors I, II, and III included 7, 8 and 3 items, respectively. All factor loadings were 0.54 or higher. Table 1 shows the factors with item loadings and the correlations among factors.

The 7 items for Factor I suggested purposefulness, motivation for learning, hopefulness, positive engagement in nursing and so on. This factor was hence labeled 'Positivity in nursing'. The 8 items on Factor II represented adaptability, flexibility and a balanced perspective of human relationships and was therefore labeled 'Interpersonal skills'. The 3 items on Factor III were all concerned with flexible response to a new occupational setting and were hence labeled 'Adaptability in the workplace'. 
Table 1. Factors with Item Loadings

\begin{tabular}{|c|c|c|c|}
\hline The literal English translation of items originally written in Japanese & $\mathbf{I}$ & II & III \\
\hline \multicolumn{4}{|l|}{ Factor I: Positivity in nursing } \\
\hline I have high aims in my career as a nurse. & 0.84 & -0.05 & -0.02 \\
\hline As I work, I try to learn to get better at nursing. & 0.75 & -0.05 & -0.06 \\
\hline As a nurse, I am more interested in nursing and patients than other nurses are. & 0.70 & 0.04 & 0.07 \\
\hline In my opinion, being a nurse is not always the path to happiness. & -0.68 & -0.10 & 0.23 \\
\hline My future as a nurse is full of bright hopes. & 0.67 & 0.12 & -0.08 \\
\hline I always make an effort as a nurse. & 0.66 & -0.04 & 0.17 \\
\hline A role with a heavy responsibility presents a difficult challenge to me. & 0.54 & 0.02 & 0.24 \\
\hline \multicolumn{4}{|l|}{ Factor II: Interpersonal skills } \\
\hline I can cooperate with the managers and co-workers I actually dislike. & -0.00 & 0.73 & -0.02 \\
\hline I have the ability to adapt easily to various types of managers and co-workers. & -0.02 & 0.73 & 0.02 \\
\hline I can cooperate with a newcomer in my workplace. & 0.06 & 0.68 & 0.07 \\
\hline $\begin{array}{l}\text { I can remain levelheaded and continue working even when distracted by personal } \\
\text { problems. }\end{array}$ & -0.21 & 0.68 & 0.33 \\
\hline $\begin{array}{l}\text { I can manage to continue working even when I have some troubles weighing on my } \\
\text { mind. }\end{array}$ & 0.03 & 0.64 & 0.04 \\
\hline I am able to remain calm even in distressing circumstances. & 0.05 & 0.63 & -0.02 \\
\hline I do not adapt well to working with reserved or hostile co-workers. & -0.04 & -0.61 & 0.13 \\
\hline I can remain calm even when provoked to anger. & 0.15 & 0.55 & -0.25 \\
\hline \multicolumn{4}{|l|}{ Factor III: Adaptability in the workplace } \\
\hline I like experiencing new situations on the job. & 0.06 & 0.07 & 0.76 \\
\hline I find it quite easy to learn new things on the job. & -0.10 & -0.01 & 0.71 \\
\hline I can enjoy learning the function and operation of medical electronics & 0.24 & -0.13 & 0.63 \\
\hline Correlation Matrix & I & II & III \\
\hline I & - & 0.28 & 0.36 \\
\hline II & & - & 0.18 \\
\hline
\end{tabular}

\subsection{Resilience and other measures}

To assess the relationship of resilience with hardiness, self-esteem, depression and burnout, the correlation coefficients were calculated between the RSN and the other four measures. Table 2 shows the relationship of the RSN with the other measures.

Table 2. Correlations between the RSN and the other scales $(\mathrm{N}=313)$

\begin{tabular}{|c|c|c|c|c|c|c|c|c|c|c|c|}
\hline & RSN & PN & IS & $\mathbf{R N}$ & Beck & SE & $\overline{B E}$ & BC & BI & HC & HP \\
\hline RSN & - & $0.75^{* *}$ & $0.63^{* *}$ & $0.56^{* *}$ & $-0.26^{* *}$ & $0.38^{* *}$ & $-0.31^{* *}$ & $-0.27^{* *}$ & $-0.30^{* *}$ & $0.47^{* *}$ & $0.27^{* *}$ \\
\hline PN & & - & $0.32^{* *}$ & $0.45^{* *}$ & $-0.25^{* *}$ & $0.38^{* *}$ & $-0.34^{* *}$ & $-0.25^{* *}$ & $-0.39^{* *}$ & $0.54^{* *}$ & $0.36^{* *}$ \\
\hline IS & & & - & $0.18^{* *}$ & $-0.29^{* *}$ & $0.31^{* *}$ & $-0.36^{* *}$ & $-0.29^{* *}$ & $-0.15^{* *}$ & $0.36^{* *}$ & $0.31^{* *}$ \\
\hline $\mathrm{RN}$ & & & & - & $-0.14^{*}$ & $0.22^{* *}$ & $-0.16^{* *}$ & 0.04 & $-0.21^{* *}$ & $0.25^{* *}$ & 0.04 \\
\hline Beck & & & & & - & $-0.51^{* *}$ & $0.58^{* *}$ & $0.35^{* *}$ & $0.22^{* *}$ & $-0.57^{* *}$ & $-0.57^{* *}$ \\
\hline SE & & & & & & - & $-0.45^{* *}$ & $-0.37^{* *}$ & $-0.41^{* *}$ & $0.44^{* *}$ & $0.35^{* *}$ \\
\hline $\mathrm{BE}$ & & & & & & & - & $0.48^{* *}$ & $0.24^{* *}$ & $-0.54^{* *}$ & $-0.44^{* *}$ \\
\hline $\mathrm{BC}$ & & & & & & & & & $0.18^{* *}$ & $-0.38^{* *}$ & $-0.42^{* *}$ \\
\hline BI & & & & & & & & & - & $-0.25^{* *}$ & $-0.18^{* *}$ \\
\hline $\mathrm{HC}$ & & & & & & & & & & - & $0.70^{* *}$ \\
\hline HP & & & & & & & & & & & - \\
\hline
\end{tabular}

** $p<.01 * p<.05$

Note: $\mathrm{RSN}=$ the total score of the RSN; PN = Positivity in nursing; IS = Interpersonal skills; RN = Adaptability in the workplace; Beck= Beck Depression Inventory; SE = the Japanese Self-Esteem Scale; $\mathrm{BE}=$ Burnout, exhaustion; $\mathrm{BC}=$ Burnout, cynicism; $\mathrm{BI}=$ Burnout, inefficacy; $\mathrm{HC}=$ Hardiness, controllability; $\mathrm{HP}=$ Hardiness, positive thinking 
Significant positive correlations were found between the total score of the RSN and the score of the Japanese Self-Esteem Scale, and between each of the three factors of the RSN and the score of the Japanese Self-Esteem Scale (i.e., nurses exhibiting higher levels of resilience experienced higher level of self-esteem). Significant positive correlations were also found between the total score and each of the three factors of the RSN on the one hand, and the scores of the Japanese version of Hardiness Personality Scale on the other (i.e. nurses exhibiting higher levels of resilience experienced higher levels of hardiness). Significant negative correlations were found between the total score and each of the three factors of the RSN on the one hand, and the scores of the Japanese version of Beck Depression Inventory and the Japanese version of Burnout Scale on the other (i.e. nurses exhibiting higher levels of resilience experienced less depression and burnout).

\subsection{I nternal consistency reliability estimates of the RSN}

The levels of Cronbach's alpha for the overall RSN, as well as each of the three factors, were respectable as follows: .74 in the overall RSN, .64 in 'Positivity in nursing', .63 in 'Interpersonal skills', .61 in 'Adaptability in the workplace'.

\section{Discussion}

The principal factor method suggested a three-factor solution. Each of the three factors were labeled 'Positivity in nursing', 'Interpersonal skills', and 'Adaptability in the workplace', respectively. All of the three factors reflected characteristics of resilience as had already been indicated by previous studies: 'personal competence' and 'acceptance of

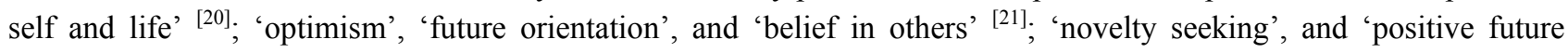

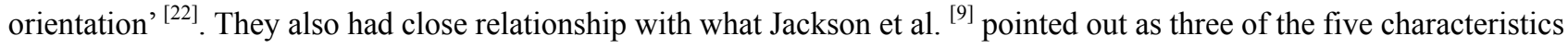
of nurses' resilience; namely, building positive nurturing professional relationships and networks; maintaining positivity; and achieving life balance and spirituality. They consequently provided support for the construct validity of the RSN.

The internal consistency reliability of the RSN was supported by the levels of Cronbach's alpha for the overall RSN as well as each of the three factors.

The hypotheses were supported with significant correlations of the RSN with well-established measures of self-esteem, hardiness, depression and burnout. As we expected, the RSN was found to have positive correlation with the former two and negative correlation with the latter two. In other words, nurses who possess higher levels of resilience are most likely to have more hardiness and a higher self-esteem. Also, there are tendencies for resilient nurses to experience less depression and burnout.

At the same time, the positive correlation values between resilience and self-esteem were mostly weak. These data imply that those who are resilient may not always have much self-esteem and that even those who have low resilience may nevertheless possess high self-esteem. Supposedly, resilience associated with learning from failures and adversities does not lead to self-esteem alone, but leads to a balance between accurate self-knowledge and respect for others.

The largest positive correlation value of 0.47 was found between resilience and the controllability dimension of hardiness. Hardiness is a personality style comprising characteristics like commitment, control and challenge ${ }^{[23]}$. Indeed, it has been studied in a somewhat different context, such as business executives under life stress ${ }^{[24]}$. Yet, there are theoretical grounds for expecting resilience and hardiness to be related. Bonanno ${ }^{[25]}$ indicated hardiness, together with self-enhancement, repressive coping, positive emotion and laughter, as one of the distinct dimensions suggestive of different types of resilience. In our study, the Japanese Hardiness Scale 20 was applied, because it is the only psychological scale currently available in the Japanese language related to hardiness. The moderate correlation can show the possibility of a common factor to exist underlying resilience and hardiness, despite theoretically different concepts.

The negative correlation values between resilience and depression and between resilience and burnout also showed only modest correlations. They suggest that those who are not resilient do not necessarily suffer from depression and burnout and that, conversely, in some cases even nurses with high resilience would fall in a state of depression and burnout. 
The weak association between resilience and depression questions the simple explanation that resilience prevents depression. Presumably, this is due to the fact that resilience is context-dependent and that depression is not. This study deals with resilience manifested in the context of psychiatric hospitals. On the other hand, depression is a neurobehavioral disorder that does not depend solely on a particular context. For understanding the relationship between resilience and depression, a multilevel perspective is necessary. As Silk et al. ${ }^{[26]}$ discussed, mediation and moderation across social and neurobiological contexts influence the effects of resilient processes. In the context of psychiatric hospitals, it is likely that the level of workplace adversity has the potential to influence the benefits of resilience processes against depression. If the total magnitude of stress exceeded their allowable limit, even resilient nurses would fall into a state of depression. On the contrary, if the amount of workplace stress is within their capacity, nurses with low resilience could escape from depression. The same would be partly true of the weak correlation between resilience and burnout, although burnout is more context-dependent than depression.

The relationship of nurses' resilience and their coping strategies remains unsolved. According to Lazarus ${ }^{[27]}$, the coping response is categorized into problem-focused coping and emotion-focused coping. Based on a sample of intensive care unit nurses, Burgess et al. ${ }^{[28]}$ found that certain personality traits, such as openness, agreeableness and conscientiousness, were associated with problem-solving copying strategies. Likewise, there is a possibility that nurses working for psychiatric hospitals would show the association between resilience and certain coping response.

The generalization of the results from this research in regard to nurses working for other psychiatric hospitals in Japan should be taken into further deliberation. This is because nurses who gave information regarding resilience and other mental health states worked for hospitals located in rural areas in Japan. According to socio-cultural differences, there may be a wide variation in the levels of resilience and its related variables in the workplaces within this country.

\section{Acknowledgement}

This research was supported by a grant for Research Support Foundation from the Juntendo Psychiatric Institute Fund in the financial year 2012 (Heisei 24).

\section{References}

[1] Estryn-Behar M, Kaminski M, Peigne E, Bonnet N, Vaichere E, Gozlan C, et al . Stress at work and mental health status among female hospital workers. Br J Ind Med. 1990; 47: 20-28. PMid:2310704

[2] Chang EM, Hancock KM, Johnson A, Daly J, Jackson D. Role stress in nurses: Review of related factors and strategies for moving forward. Nursing and Health Sciences. 2005; 7: 57-65. PMid:15670007 http://dx.doi.org/10.1111/j.1442-2018.2005.00221.x

[3] Hutchinson M, Vickers M, Jackson D, Wilkes L. Work-place bullying in nursing towards a more critical organizational perspectives. Nurs Inq. 2006; 13: 118-126. PMid:16700755 http://dx.doi.org/10.1111/j.1440-1800.2006.00314.x

[4] Ihara H, Ogata H, Inuzuka A, Ohta N, Nagai T. Incidents of Violence and Verbal Abuse from Patients and Their Relatives against Nurses in Dokkyo Medical University Koshigaya Hospital. Dokkyo Journal of Medical Science. 2007; 37: 1-8.

[5] Applebaum PS, Dimieri RJ. Protecting staff from assaults by patients. OSHA steps in Psychiatric Services. 1995; 46: $333-338$.

[6] Nijman HLI, Campro JMLG, Ravelli DP, et al. A tentative model of aggression on inpatient psychiatric wards. Psychiatric Services. 1998; 50: 832-834.

[7] Ito H, Eisen SV, Sedere LI, et al. Facotors affecting psychiatric nurses' intention to leave their current job. Psychiatri Serv. 2001; 52: 232-234. PMid:11157125 http://dx.doi.org/10.1176/appi.ps.52.2.232

[8] Jacelon C. The trait and process of resilience. J Adv Nurs. 1997; 25: 123-129. PMid:9004020 http://dx.doi.org/10.1046/j.1365-2648.1997.1997025123.x

[9] Jackson D, Firtko A, Edenborough M. Personal resilience as a strategy for surviving and thriving in the face of workplace adversity: a literature review. J Adv Nurs. 2007; 60: 1-9. PMid:17824934 http://dx.doi.org/10.1111/j.1365-2648.2007.04412.x

[10] Fredrickson BL, Mancuso RA, Branigan C, Tugade MM. The undoing effect of positive emotion. Motiv Emot. 2000; $24: 237-258$. PMid:21731120 http://dx.doi.org/10.1023/A:1010796329158

[11] Tugade M, Fredrickson B. Resilient individuals use emotions to bounce back from negative emotional experiences. Journal of Personality and Social Psychology. 2004; 86: 320-333. PMid:14769087 http://dx.doi.org/10.1037/0022-3514.86.2.320

Published by Sciedu Press 
[12] Rutter M. Resilience in the face of adversity: protective factors and resistance to psychiatric disorder. Br J Psychiatry. 1985; 147: 598-611. PMid:3830321 http://dx.doi.org/10.1192/bjp.147.6.598

[13] Ogata H, Ihara H, Inuzuka Q, Ohta N, Mizuno M.Development of Resilience Scale for Nurses. Its Reliability and Validity. Seishinigaku. 2010; 52: 785-792 (in Japanese).

[14] Ihara H, Ogata H, Inuzuka A, Ohta N, Nagai T, Mizuno M. Development and psychometric validation of the Resilience Scales for Nurses. Jpn J Gen Hosp Psychiatry. 2010; 22: 210-220.

[15] Rosenberg M. Society and the adolescent self-image. Princeton University Press. 1965

[16] Yamamoto M, Matsui Y, Yamanari Y. Recognized aspects of self. Kyoiku Shinrigaku Kenkyu 1982; 30: 64-68 (in Japanese).

[17] Kawashima M, Tojo M, Matuoka Y, Tanaka K. A study on the development of Hardiness personality scale. Okayama Daigaku Kyoikugakubu Kenkyushuroku. 2001; 116: 25-31(in Japanese).

[18] Hayashi K, Takimoto T. Validation of Beck Depression Inventory (BDI) and examination of the relationship between depression and self-efficacy. Hakubai Gakuen Tankidaigaku Kiyo. 1991; 27: 43-52.

[19] Nishibori Y, Moroi K. Burn-out and interpersonal environment among nurses. Kango Kenkyu. 2000; 33: 245- 255(in Japanese).

[20] Wagnild GM, Young HM. Development and psychometric evaluation of the Resilience Scale. J Nurs Meas. 1993; 1: 165-178. PMid:7850498

[21] Jew CL, Green KE, Kroger J. Development and validation of a measure of resiliency. Meas Eval Counsel Dev. 1999 ; $32: 75-89$.

[22] Oshio A, Nakaya M, Kaneko H, Nagamine S. Development and Validation of an Adolescent Resilience Scale. Japanese Journal of Counseling Science. 2002; 35: 57-65(in Japanese).

[23] Kobasa SC, Maddi SR, Kahn SJ. Hardiness and health: a prospective study. J Personal Soc Psychol. 1982; $42: 168-177$. PMid:7057354 http://dx.doi.org/10.1037/0022-3514.42.1.168

[24] Maddi SR, Kobasa SC. The Hardy Executive: Health under Stress. Dow Jones-Irwin, Homewood IL. 1984.

[25] Bonanno GA. Loss, trauma, and human resilience. Am Psychologist. 2004; 59: 20-28. PMid:14736317 http://dx.doi.org/10.1037/0003-066X.59.1.20

[26] Silk JS, Vanderbilt-Adriance E, Shaw DS, Forbes EE, Whalen DJ, Ryan ND, Dahl RE. Resilience among children and adolescents at risk for depression: mediation and moderation across social and neurobiological contexts. Dev Psychopathol. 2007; 19 : 841-65. PMid:17705905 http://dx.doi.org/10.1017/S0954579407000417

[27] Lazarus R. Psychological Stress and the Coping Process. New York, McGraw Hill, 1966

[28] Burgess L, Irvine F, Wallymahmed A. Personality, stress and coping in intensive care nurses: a descriptive exploratory study. Nursing in Critical Care. 2010; 15: 120-140. PMid:20500651 http://dx.doi.org/10.1111/j.1478-5153.2009.00384.x 